\title{
JORGE LUIS BORGES Y LA AMBIVALENTE MITIFACIÓN DE SU ABUELO PATERNO
}

Al estudiar desde un punto de vista literario un documento anónimo sobre la revolución de 1874 en la Argentina ${ }^{1}$ tuve que rastrear la información histórica sobre sus conexiones - supuestas o comprobadas- en distintos puntos del país². Esto me llevó,

1 "En los márgenes de la literatura: un informe sobre la revolución de 1874 en la Argentina", en Dialogo, Studi in Onore di Lore Terracini, a cura di Inoria Pepe Sarno, Bulzoni, Roma, 1990, t. 1, pp. 45-53.

${ }^{2}$ Al finalizar la presidencia de Sarmiento hay dos candidatos bonaerenses (Bartolomé Mitre por el partido Nacionalista y Adolfo Alsina por el Autonomista) además de Nicolás Avellaneda apoyado por las provincias del interior y por Sarmiento. La elección de diputados de Buenos Aires al Congreso Nacional desencadenó el conflicto. Al fraude propio de la época (el voto no era ni universal ni secreto) se unió el convenio de Alsina con Avellaneda (retirar su candidatura a presidente a cambio de apoyo para validar los diplomas de los diputados alsinistas en contra de los mitristas). Así se desató un levantamiento militar cuya cabeza era Mitre, secundado por Ignacio Rivas y Francisco Borges, jefes de frontera en Buenos Aires, y José Miguel Arredondo con influencias en el oeste y el centro: San Luis, Córdoba y zona cuyana excepto Mendoza, además de la escasa marina de guerra en el este. Mitre puso como condición no moverse contra Sarmiento sino el día 12 de octubre de 1874, fecha de la trasmisión del mando al presidente electo, Nicolás Avellaneda. Se creía contar con los Taboada en el norte, que no respondieron, y se sabe que se intentó atraer a López Jordán en Entre Ríos (cf. M. A. DuARTe, "Repercusiones de la revolución de 1874. La misión de José Hernández a Buenos Aires", Investigaciones y Ensayos, 1990, núm. 40, 159-189). A Mitre lo seguían civiles porteños que formaron el "Comité Revolucionario" y estancieros de la provincia de Buenos Aires. Sarmiento intentó neutralizar a Arredondo por medio del General Teófilo Ivanowski, entonces al mando de las fuerzas de Villa Mercedes (San Luis), pero éstas apoyaron la revolución e Ivanowski fue muerto el 25 de septiembre por Crisólogo Frías, enviado de Arredondo, y su escolta. Sarmiento escribió dos cartas a Rivas y una a Borges para que se mantuvieran fieles al gobierno. Rivas se negó, pero Borges adoptó la actitud de devolver al presidente las fuerzas que tenía a su mando (tres regimientos 
después, a conocer en forma más precisa la actuación del corone Francisco Borges en esa ocasión, y a interrogarme sobre los poe mas que su nieto le dedicó a lo largo de su vida.

$\mathrm{Si}$ con el primero incorporaba a la atención crítica un textı marginal, para desplazar límites genéricos y enriquecer los mun dos culturales y la constitución del campo intelectual, ahora $\mathrm{m}$ propongo otros problemas que atañen de algún modo a la ge

de caballería de línea y uno de infantería), renunciar a su cargo y cumplir 1 pactado con los rebeldes. Pasó a Buenos Aires donde estuvo arrestado en $\mathbf{s}$ domicilio y se fugó a Montevideo para reunirse con Mitre. Volvió al país co él, desembarcó en El Tuyú el 26 de octubre, siguió las marchas del famos semicírculo de ciento ochenta leguas por campos y caminos anegados - dist ñado por la estrategia de Mitre- y el día de "La Verde" lo encontró al frent de la llamada "Brigada Borges" formada por dos batallones, uno de ellos pc tropas del $4^{\circ}$ de caballería de línea, el 26 de noviembre de 1874 . Cuando dak una orden al teniente coronel Palacios, jefe del $4^{\circ}$ batallón, recibió dos bali zos simultáneos que le causaron, después de dos días, la muerte. Al compr bar que la excelente posición del teniente coronel José Ignacio Arias - cc mejor armamento, gente más conocedora de su manejo y bien parapetadosera imbatible, Mitre decidió capitular de acuerdo también con la opinión c Rivas. Dio orden de retirada y en el camino a Junín, donde firmó las bas de la capitulación con Arias, fueron desertando unos mil quinientos guardi: nacionales. En cuanto a la suposición de que F. Borges quiso hacerse mat: en "La Verde" unos se apoyan en el doble efecto de la muerte de Ivanows a manos de Arredondo y el repudio de sus camaradas rebeldes porque le d volvió a Sarmiento las tropas de su frontera, o sólo por esto último. En cont de la interpretación hay dos datos. Uno es que aconsejó a Mitre -inútilme te- que continuara combatiendo porque estaban por agotarse las municion de Arias. El otro lo muestra dando órdenes al subordinado que debía carg (véase Edmundo Givati Bernasconi, Entre dos presidencias, Círculo Milita Buenos Aires, 1965, p. 324) y destruye la romántica visión de quien avanzal “. . tranquilamente, con sus brazos cruzados y la fisonomía iluminada $p$ una expresión de melancólica bravura" (cf: JACINTO YABEN, Biografías argen nas y sudamericanas, Metrópolis, Buenos Aires, 1938, t. 1, p. 640). Para la rev lución de 1874 véanse Florencio del Mármol, Noticias y documentos sobre revolución de setiembre de 1874, Buenos Aires, 1876; E. Civati Bernasconi, c cit. (con mucho de elaboración poética anovelada reconocida por el auto Luis Alberto Romero, Los golpes militares: 1812-1955, Carlos Pérez Editc Buenos Aires, 1969; Tulio Halperín Donghi, Proyecto y construcción de una, ción (Argentina 1846-1880), Biblioteca Ayacucho, Caracas, 1980; FÉlix BEs Historia de las guerras argentinas. De la independencia, internacionales, civiles y con indios, 2 ts., Peuser, Buenos Aires, 1960. Para la muerte de Ivanowski y tradición folklórica Olga Fernández Latour (ed.), Cantares históricos de la $t$ dición argentina, Instituto Nacional de Investigaciones Folklóricas, Buenos 1 res, 1960, pp. 334-335. 
nética textual y a su capacidad de ampliar la red de sus confrontaciones ${ }^{3}$

Tomaré cinco poemas que Jorge Luis Borges dedicó a su abuelo, herido mortalmente en el desastre de "La Verde" durante la revolución mitrista, el 26 de noviembre de 1874. Todos suponen una reelaboración de hechos históricos, un entramado de lecturas, ecos folklóricos o de la propia tradición oral familiar, connotaciones épicas o personales. Todos muestran constantes que los enlazan y variaciones que los diversifican, a veces por reescrituras parciales o por ademanes que apuntan a otros de sus textos poéticos o de su prosa ficcional.

1. Fue el primero: "Inscripción sepulcral. Para el coronel don Francisco Borges, mi abuelo" (aparecido en Fervor de Buenos Aires, 1923, libro sin lugar ni paginación, por el cual cito). Cuando reunió su obra lírica en Poemas [1922-1943], Losada, Buenos Aires, 1943, lo eliminó definitivamente sin volver a rescatarlo. Es sin duda una poesía endeble, y la borró quizá por eso, o porque conservaba en el grupo perteneciente a Fervor... otra "Inscripción sepulcral", p. 30, con la dedicatoria "Para el coronel don Isidoro Suárez, mi bisabuelo", o porque en el mismo volumen incluía entre el grupo de Luna de enfrente, p. 93, otro poema en homenaje al abuelo Borges, o por todas esas razones a la vez.

\section{INSCRIPCIÓN SEPULCRAL}

Para el coronel don Francisco Borges, mi abuelo.

Las cariñosas lomas orientales, los ardientes esteros paraguayos y la pampa rendida fueron ante tu alma

${ }^{3}$ Para la nueva crítica genética, según la escuela francesa, pueden consultarse L. Hay, R. Debray-GenetTe y H. MitTerand, Essais de critique génétique, Flammarion, Paris, 1979; L. HAY, "L'amont de l'écriture", Camets d'Ecrivains, 1 (1990), 7-22; A. M. Barrenechea y J. Cortázar, Cuaderno de bitácora de "Rayuela", Sudamericana, Buenos Aires, 1983; y la "Bibliographie génerale" que ofrecen A. Grésillon, J-L. Lebrave y C. Viollet, Proust à la lettre. Les intermittences de l'écriture, Du Lérot Éditeur, Tusson (Charante), 1990, pp. 207-210. Para las ediciones de Borges cf. Horacio J. BECCO, Jorge Luis Borges. Bibliografía total (1923-1973), Casa Pardo, Buenos Aires, 1973. Agradezco a Sara del Carril su gentil y paciente colaboración para completar los datos de las publicaciones de Emecé. 
una sola violencia continuada.

En el combate de La Verde

desbarató tanto valor la muerte.

Si esta vida contigo fue acerada

y el corazón, airada muchedumbre

se te agolpó en el pecho,

ruego al justo destino

aliste para ti toda la dicha

y que toda la inmortalidad sea contigo.

El texto borrado (un conjunto unitario de trece versos irregulares, con predominio de endecasílabos y heptasílabos) reunía lí experiencia del hombre dedicado al duro oficio de la guerra: ba. tallas en el Uruguay, en el Paraguay o en la frontera de Bueno: Aires "fueron ante tu alma / una sola violencia continuada". Nc importa que las maticen o las diferencien ciertas notas: el adje tivo "cariñosas" mitiga la lucha en el Uruguay; "ardientes' unido a los "esteros" dramatiza, en cambio, la guerra del Para guay; "rendida" junto a "la pampa", escenario de las líneas d frontera indígena, tiene la ambigüedad de significación de 'ven cida, sometida, sumisa' y al mismo tiempo de 'con entrega amo rosa' lo cual da al sintagma la duplicidad (complicidad) del ton' épico y el tamizado por la emoción sentimental. En especial si $\epsilon$ lector conoce que el imaginario poético de Borges está saturad por la presencia de la llanura, la nota melancólica de los ocasos la exaltación de los amaneceres, la visión del círculo del horizor te que prefigura a la Divinidad, la infinitud espacial y temporal

La violencia persiste bajo algunas formas más barrocas prc pias de su obra juvenil. En "acerada", juega con el nivel sє mántico, sintáctico y retórico, introduciendo al lector en un tos bellino de interpretaciones y resonancias: "Si esta vida contig fue acerada".

Semánticamente caben las interpretaciones: 'de acero, par' cida a él', fig. 'fuerte o de mucha resistencia', 'incisiva, morda: penetrante'; pero si sabemos la preferencia de su primera épor por revitalizar significaciones que vuelven a las fuentes latin: surge también ¿con más peso? 'estar armada, o portar armas, e pecialmente espada'. La sintaxis propone que la frase verbal st leída como una voz pasiva en la que el abuelo sería el agen

${ }^{4}$ Ana María Barrenechea, La expresión de la irrealidad en la obra de Jo: Luis Borges, El Colegio de México, México, 1957. [Nueva ed.: Centro Edit de América Latina, Buenos Aires, 1973, sin bibliografia y con tres apéndice 
-reconozco que bajo una fórmula poco común: "contigo" - y la vida el sujeto paciente, es decir que la vida fue convertida en un perpetuo guerrear por el abuelo; o también, si se la considera como un predicado nominal, del que la vida sea sujeto y "contigo" un complemento del adjetivo "acerada", se concluiría que la vida fue como una espada con el abuelo, estuvo armada contra él. En este punto se cruzaría la lectura retórica de una posible hipálage, figura muy querida por el poeta, que en este caso habría trasladado al sustantivo "vida", el adjetivo "acerada", que se refiere en realidad al abuelo, el héroe que guerreó con la espada.

En "el corazón, airada muchedumbre" revela las "astucias" de Quevedo y de Diego Torres de Villarroel, su heredero, al utilizar la multiplicidad de los colectivos para "engrandecer una cosa simple $[\ldots]$ con cierta connotación de desorden y pululación de vida o de muerte"5.

Los dos versos finales que resumen su perpetuo batallar son muy escuetos, como corresponde al modelo epitafio: "Inscripción sepulcral", que debe ser breve pero sentencioso. "En el combate de La Verde / desbarató tanto valor la muerte". Pero los tres que cierran el poema con un ruego piadoso y patriótico decaen y languidecen a pesar de su intento de elevarse al tono épico.

2. El segundo poema "Al coronel Francisco Borges (18331874)" fue recogido en libro por primera vez en Poemas [19221943], Losada, Buenos Aires, 1943, y lo incluyó entonces dentro del grupo de Luna de enfrente, en pp. 93-94, pero en realidad no lo había puesto en la edición original de esa obra de 1925 ni en la siguiente de Cuaderno San Martín, de 1929.

Cuando apareció la colección de Obras completas, Emecé, Buenos Aires, en volúmenes separados, el núm. 2, Poemas, 1923$1953,1^{a}$ ed. 1954, continuó incluyéndolo dentro de Luna de enfrente, y ocurrió lo mismo en la $2^{\mathrm{a}}, 1958$; la $3^{\mathrm{a}}$ que ya comenzó a llamarse Obra poética, 1923-1958, c. 1962; la $4^{\text {a }}$ Obra poética $1923-1964,1964 ;$ la $5^{a}, 1965$; y la $6^{\text {a }}, 1966$, por la que cito. Lo eliminó definitivamente en la $7^{\mathrm{a}}, 1967$, y en todas sus apariciones se mantuvo invariable salvo en la corrección de la fecha del verso 11: "El día 28..." que desde la $4^{a}$ ed. en adelante cambió por "El día 26..." ateniéndose a la verdad histórica ${ }^{6}$.

${ }^{5}$ Ibid., p. 38.

${ }^{6}$ En efecto Borges fue evacuado y murió a los dos días. Civati BerNASCONI, op. cit., p. 327 y E. GutIÉRREZ, Croquis y siluetas militares (1886), 


\section{AL CORONEL FRANCISCO BORGES}

(1833-1874)

Porque eso fue tu vida:

Una cosa que arrastran las batallas.

El honor, la tristeza, la soledad

y el inútil coraje.

Montevideo y los mazorqueros de Oribe,

las resueltas cuchillas orientales,

los febriles esteros del Paraguay,

dos balas paraguayas,

la montonera jordanista en los montes,

la pampa de Catriel y de Martín Fierro.

El día 26 de noviembre de 1874 , para que te viera la muerte, montabas un caballo plateado $y$ te envolviste en un poncho blanco.

El día 28 de noviembre de 1874 , morías con dos balas en el estómago (p. 85).

Este texto comienza como el anterior en cuanto al nivel de relatado, con la existencia guerrera del abuelo, antes de referir a su muerte por las heridas recibidas en la batalla de "La Ve de" ; pero cambia en lo que corresponde al nivel formal. Con se ve narra por bloques o grupos de versos - no diría estrofas separados por blancos, y además invierte los procedimientos.

Primero inserta dos versos definitorios: "Porque eso fue vida: / Una cosa que arrastran las batallas" (eco del verso "us sola violencia continuada", que sintetiza la enumeración campañas guerreras en el poema que acabo de comentar). $\mathrm{Pe}$ dentro de este bloque, ya la línea primera señala con un neutr el deíctico "eso" (es decir un vacío), a la siguiente, que la defi con otro vacío "una cosa".

El bloque siguiente parece querer entrar en la intimidad c abuelo que Borges no llegó a conocer, con una enumeración

Hachette, Buenos Aires, 1956, p. 84, relatan sus últimos momentos con riaciones de datos emotivos o pintorescos, por ejemplo el que después muerto lo llevan a enterrar retobado en un cuero, según sus propias predicr nes, como acota Gutiérrez con rasgo de humor negro. 
cuatro frases nominales: "El honor, la tristeza, la soledad / y el inútil coraje". Por una parte, ellas simulan llenar los huecos, y por otra deberán ser llenadas con fechas, lugares, acciones que se sucederán a continuación para dar falsas seguridades de conocer "el muerto, el increíble", las "frecuencias irrecuperables". Otros poemas volverán sobre lo hipotético de esta intimidad en realidad impenetrable o la afirmación del arte como invención y no como copia, la esencial unidad de los hombres junto con su concreta y precisa encrucijada mortal, las aporías y las ambigüedades.

Después de un blanco sigue la conocida enumeración de las experiencias guerreras del abuelo con variantes y adiciones ahora más numerosas y concretas. Figura el Uruguay donde agrega la mazorca y cambia la adjetivación. Dice "las resueltas" - no las "cariñosas" como antes- "cuchillas" - no "lomas"-; aunque la palabra cuchilla no difiera mucho en cuanto al referente sí difiere en el matiz agresivo de la connotación; "resueltas" acentúa emotivamente la voluntad más propia de la actitud bélica y reúne el doble significado de 'determinado, audaz, arrojado, decidido' y el de 'haber desatado una dificultad, concluido un problema', junto con el uso retórico posible de la hipálage que aplica a las cuchillas la calificación que corresponde al coronel. El Paraguay cambia sus "ardientes esteros" por "febriles" calificación igualmente patética, también con hipálage en este caso, al que une la precisión del dato "dos balas" que están históricamente documentadas. Agrega Entre Ríos en la época de las rebeliones de López Jordán, con montoneras posteriores a las de Rosas, situadas en el ámbito áspero de "los montes". La vida de los fortines contra los indios muestra una rasgo borgeano que persiste en toda su producción. El ámbito de la llanura conjuga un nombre histórico y uno literario, es "la pampa de Catriel y de Martín Fierro"'?.

7 Borges debe de aludir a Cipriano Catriel, "indio amigo" que había ayudado a los jefes de frontera contra los malones de Calfucurá. Precisamente Calfucurá encabezó el famoso Malón de San Carlos (1872) rechazado según unos por la intervención del abuelo Francisco (E. Gutí́rRez, op. cit.), por Rivas y/o Catriel según otros (R. Piccirilli et al., Diccionario histórico argentino, EHA, Buenos Aires, 1953; y D. Abad de Santillán, Gran Enciclopedia Argentina, EDIAR, Buenos Aires, 1956). Rivas había incorporado al llamado "Ejército Constitucional" de los revolucionarios un contingente de 1500 indios mandados por Cipriano, pero Mitre insistió en que se retiraran antes de "La Verde". Más tarde, las discrepancias entre los hermanos Cipriano (Ca- 
Un penúltimo bloque de cuatro versos irregulares resume la visión épica y mítica del desastre de "La Verde":

El día 26 de noviembre de 1874 , para que te viera la muerte, montabas un caballo plateado ${ }^{8}$ $\mathrm{y}$ te envolviste en un poncho blanco.

No hay documentación de que fuera así. Quizá el detalle le llegć al autor por boca de la abuela o por tradición oral de la familia. quizá conocía también que el saber popular atribuye al color blanco la capacidad de atraer el rayo, o que se dijo que el padre de José Hernández, envuelto en un poncho blanco, o montadc en un caballo blanco ${ }^{9}$, murió fulminado por el rayo, quizá fur invención del propio nieto o todo a la vez confluyó para dibuja: en su imaginario poético la visión trágica del guerrero que busci la muerte.

Después de otro espacio de separación, el poema se cierra cor fraseo preciso que repite el primer verso del grupo anterior (salvı la corrección del día), repetición que es la única marca retóric: de un pareado irregular que se caracteriza por la desnudez realis ta y se sujeta (se limita) a consignar los datos: "El día 28 de nc viembre de 1874 / morías con dos balas en el estómago".

Los datos son históricos en el detalle de las balas, y desde 1 rectificación del verso 11 en la ed. $4^{\text {a }}$ también en la fecha, per

cique general) y Juan José Catriel concluyeron en crímenes recíprocos, y primero murió decapitado por el segundo (según La Prensa, diario prı revolucionrio, con complicidad del ejército gubernamental que fue testigo $\mathrm{p}$ : sivo, apud Civati Bernasconi, op. cit., pp. 308-311).

${ }^{8}$ Plateado 'pelaje blanco que sobre cuero oscuro produce efectos de refl jo metálico' (cf. Tito SAUbiDEt, Vocabulario y refranero criollo, Kraft, Buen Aires, 1943). Emilio Solanet, Paisajes criollos, Kraft, Buenos Aires, 195 pp. 25-31, habla, entre las "Subdivisiones" del blanco, de "El blanco plateaa cuando es lustroso y brillante" pero enseguida hace una cita de 1739 de i plateado, llamándolo con el adjetivo solo, sustantivado como es costumbre cc otros pelajes.

9 Pedro de Paoli (Los motivos de "Martín Fierro" en la vida de José Herná dez. El gaucho de la argentinidad, Ciordia y Rodríguez, Buenos Aires, 1947) Fermín Chaves (La vuelta de José Hernández, Theoria, Buenos Aires, 197 p. 9) dan por muerto al padre de José Hernández el 5 de junio de 1857 fuln nado por un rayo, pero no mencionan el detalle del poncho o del caballo bla co. Su hermano Rafael Hernández no habla de esto en la biografía del famo escritor. Es creencia popular que el caballo blanco atrae el rayo, según lo 1 cuerda C. Lemée (apud E. Solanet, op. cit., p. 31). 
no lo son en las circunstancias. En las primeras versiones reforzaba la repetición, unificando el momento de la supuesta carga con el de la muerte, y escamoteaba los dos días de agonía en el hospital. A mbos efectos son los énfasis que Jorge Luis Borges se permite en la primera versión, levemente atenuada por la posterior. Digo "levemente" porque para muchos lectores pasa inadvertida la diferencia entre las fechas y persiste la impresión del destino ineluctable, de la hora señalada, que es una constante en la obra del autor (y en tradiciones universales, sin duda).

3. Un último poema de los que llevan en el título el nombre del abuelo se concentra sólo en la ocasión de su fin desastroso. Lo llama "Alusión a la muerte del coronel Francisco Borges (18331874)"'. Lo recogió en libro en El hacedor, Emecé, Buenos Aires, 1960, Obras completas, núm. 9, p. 79. Sin embargo, para fijar la cronología debe recordarse que el autor reconoció haber reunido en él papeles de muy distinta fecha, en prosa y verso. El tomo de Obra poética, 1923-1964, 4ª ed., 1964, lo incluye en el grupo correspondiente a El otro, el mismo hasta la $9^{\mathrm{a}}$ ed., 1972. La $10^{\mathrm{a}}$ ed., 1977, cambia la organización, pone las poesías de El hacedor (1960) con ese título después de las de Cuaderno... restituyendo así su pertenencia primitiva hasta la $17^{\mathrm{a}}$ ed., por la cual cito 1987, en la que recoge hasta los poemas de La cifra (1981). Paralelamente apareció en las ediciones de Emecé en volúmenes individuales de El otro, el mismo (1930-1967), I ${ }^{\mathrm{a}}$ ed., 1969 y $2^{\mathrm{a}}$ ed., 1970 y en la recopilación en un volumen de sus Obras completas, 1974, en ella bajo el grupo de El hacedor. En todas mantiene invariable el texto y solamente oscila en cambiar la fecha del nacimiento que figura en el título de 1835 a 1833.

\section{ALUSIÓN A LA MUERTE DEL CORONEL FRANCISCO BORGES (1833-1874)}

Lo dejo en el caballo, en esa hora Crepuscular en que buscó la muerte; Que de todas las horas de su suerte Ésta perdure, amarga y vencedora. Avanza por el campo la blancura ${ }^{10}$

${ }^{10}$ Entre las "Cualidades y defectos atribuidos a los de este pelo" SOlANET, op. cit., pp. 27-31, hace la historia de su prestigio en la antigüedad y entre los virreyes españoles, más como festejo y pompa de carruaje y escolta, lo cual alcanza hasta los Taboada, hombres fuertes del norte argentino en la época. También figura como cabalgadura preferida de caudillos y gobernan- 
Del caballo y del poncho. La paciente

Muerte acecha en los rifles. Tristemente

Francisco Borges va por la llanura.

Esto que lo cercaba, la metralla,

Esto que ve, la pampa desmedida,

Es lo que vio y oyó toda la vida.

Está en lo cotidiano, en la batalla.

Alto lo dejo en su épico universo

$\mathrm{Y}$ casi no tocado por el verso (p. 156).

La palabra "Alusión" del título disminuye el énfasis y produce cierto borramiento, pero el desarrollo del poema le da la brevedad y el tono severo del género epitafio y la impostación épica con lo cual parece acercarse al diseño originario del primer poe. ma "Inscripción sepulcral", publicado en Fervor de Buenos Aires No puede sorprender este circuito recorrido para llegar a sus pro pios orígenes, cuando Borges insistió en que en ese libro inicia se reconocía el hombre viejo, después de haber pasado por ur buscado localismo pintoresco y haberlo abandonado luego ${ }^{11}$.

Comienza con los versos que fijan al abuelo heroico casi come estatua ecuestre, momento explícitamente elegido por quien lo rememora: "Lo dejo en el caballo, en esa hora / Crepuscular es que buscó la muerte; / Que de todas las horas de su suerte / Ést: perdure, amarga y vencedora".

Sin embargo se trata de una estatua de naturaleza ambigua por una parte, al detenerlo lo monumentaliza (como lo harán lo dos versos que cierran el poema, según se verá). Pero el espaci y el tiempo - el círculo de la llanura y la hora crepuscular, forma constantes de su imaginario poético- subrayan la entonació

tes valientes: de Rosas, de Quiroga (en la batalla de Chacón), del.Mariscal Lr pez (en la guerra del Paraguay). Es curioso que no cite al de San Martín. Entı los jefes de frontera recuerda al general Villegas y su cuerpo tercero de líne: totalmente montado en blancos. Cuando Francisco Borges fue enviado pr Mitre a entrevistarse con el teniente coronel Arias antes de "La Verde" pal que se rindiera sin luchar ante la superioridad numérica de los rebeldes, il con una escolta de cuarenta hombres montados en caballos blancos ( ¿sería es color común en su cuerpo de línea?) Sin embargo el paisano no suele preferir y le encuentra defectos de resistencia y de visión, quizá junto a la oculta $\mathrm{s}$ perstición demoníaca.

${ }^{11}$ En el prólogo que escribió para Fervor de Buenos Aires, el 14 de agosto ، 1969, declara que ese libro: "Para mí [...] prefigura todo lo que haría dt pués" (cito por la $17^{\text {a }}$ ed. de Obra poética, p. 19). En cambio en el prólogo . Luna... rechaza su afán de buscar en esa época como obligaciones la expr sión de lo argentino y lo moderno (p. 65). 
melancólica que luego se acentúa. El par de calificativos “ amarga y vencedora" pueden interpretarse como hipálages, y su unión resulta contrastante o no, de ahí su ambigüedad. Ambos adjetivos, modificadores sintácticos del sustantivo sobreentendido (hora) como predicados nominales, proliferan en sus caminos semánticos, más si nos fijamos en que la hora elegida por el poeta para inmortalizarlo es la "hora [...] en que buscó la muerte", narrada en presente y detenida también como en un film inmovilizado ${ }^{12}$.

"Amarga" puede referirse al sujeto textual, el coronel Borges, que vivió una situación ambigua, considerado traidor por uno y otro bando en pugna aunque quisiera ser leal a ambos, también porque su nieto elige - entre las tradiciones históricas, literarias, familiares y folklóricas - la que supone que voluntariamente quiso exponerse a un peligro que era un suicidio, como la única solución honorable.

$\mathrm{Al}$ adjetivo "vencedora" puede interpretárselo como unido semánticamente a Francisco Borges y su exaltación épica o a la Muerte personificada.

Repite la creencia de que iba envuelto en un poncho y montaba un caballo blanco (menos inusitado para el lector común que el pelaje "plateado"). Es la cualidad sustantivada - "la blancura"- no el caballo que monta el prócer, no el poncho en que se envuelve, lo que se ve acercarse hacia su destino como buscando la aniquilación, mientras ésta - "la paciente muerte" - lo espera.

La vida del guerrero aparece signada por la melancolía y despojada de todo énfasis ornamental, reducida a un oficio diario sin nombres de lugares ni fechas: "Esto que lo cercaba, la metralla, / Esto que ve, la pampa desmedida, / Es lo que vio y oyó toda la vida. / Está en lo cotidiano, en la batalla". El contraste de la violencia y el infinito de la llanura, que también es un círculo y un laberinto en Borges, superan aquí el peso del ser humano y le hacen perder su individualidad, su dimensión propia.

Dicha bipolaridad se resuelve, sin embargo, en igualdad y queda reducida a la estatura del hombre que nos aparecía como anulado; lo vivido por él diariamente es lo inusitado según la perspectiva de otros. El combate, si se lee de derecha a izquierda

${ }^{12}$ No debe olvidarse que Borges escribió "Dos versiones de «Ritter, Tod und Teufel"' sobre el famoso grabado de Durero, el cual es también autor del célebre grabado que simboliza "La Melancolía". Cito por las pp. 345-346 de la misma ed. 17 donde figuran en el grupo de Elogio de la sombra (1967-1969). 
(como en escrituras semíticas), y su arrasadora explosión quedar igualados a la vida de todos los días, para todo hombre.

El pareado final cierra el poema, devolviéndolo a su tono de comienzo con monumentalidad reforzada: "Alto lo dejo en st épico universo / Y casi no tocado por el verso".

A poco que nos detengamos percibimos en él la ambigüedac y la paradoja. El autor - que conoce bien el tópico de la inmorta lidad alcanzada por el arte ${ }^{13}$, lo único que da al hombre perece dero su perduración entre los hombres - borra el lenguaje y li poesía, es decir la materia de construcción de la epopeya. Entr los dos polos del eje vertical vuelve a elevarlo: "alto"; pero si li despoja del verso, "casi", y desde el título eligió la "Alusión", par: dejarlo intocado, no le queda otra forma de arte que la estatuari: ecuestre que inmortalizó a un Gatamelata o al general Alvear, d Bourdelle (que desde la cima de su monumento puede ver las ce nizas del coronel Borges, conservadas en el cementerio de La R $\epsilon$ coleta).

Para el lector de Borges, las contradicciones de este texto ha cen eco a las de otros. Triunfo y fracaso guerrero en el abuelc unión del coraje con la soledad y la melancolía. Triunfo literari y fracaso de la posibilidad de la acción - por razones individuale y epocales - en el nieto, que exaltó el coraje de héroes y malevo: pero también "cortejó" su propia disolución ("Palabras, palabré desplazadas y mutiladas, palabras de otros fue la pobre limosn que le dejaron las horas y los siglos", "El Aleph"). A los vaiven de fusión y calculado distanciamiento entre abuelo y nieto, ve poética y sujeto textual, enunciador y enunciado, se une otra sı ñal de ambigüedad. Ésta funciona cuando se coteja lo que nars el poema con lo que narran los discursos históricos. Entoner vuelve a manifestarse, lo explícito, lo implícito y lo definitivame te borrado con respecto a la "verdad histórica" y la multiplicid de agregados, alusiones, fluctuaciones y libertades que la "verd $c$ poética" permite.

4. "Junín", fechado al pie Junín, 1966, figura en su Obra poétic 1923-1969, incluido en el grupo de El otro, el mismo y también ‘ la edición de volúmenes individuales de este poemario que hi: el mismo año Emecé. El Yo poético cuenta el viaje que hizo ‘ peregrinación a las fuentes a la actual ciudad de Junín (provine

${ }^{13}$ Cf. María Rosa Lida de Malkiel, La idea de la fama en la Edad. Me. castellana, F.C.E., México, 1952. 
de Buenos Aires) donde tuvo el cuartel general su abuelo, como cabecera de la línea de fortines contra los indios. Allí. vivió con su mujer, Frances Haslam, la abuela que le relató su encuentro con la cautiva inglesa en "Historia del guerrero y de la cautiva" (El Aleph, Losada, Buenos Aires, 1949) ${ }^{14}$.

\section{JUNÍN}

Soy, pero soy también el otro, el muerto, $\mathrm{El}$ otro de mi sangre y de mi nombre;

Soy un vago señor y soy el hombre

Que detuvo las lanzas del desierto.

Vuelvo a Junín, donde no estuve nunca,

A tu Junín, abuelo Borges. ¿Me oyes,

Sombra o ceniza última, o desoyes

En tu sueño de bronce esta voz trunca?

Acaso buscas por mis vanos ojos

El épico Junín de tus soldados,

El árbol que plantaste, los cercados

$\mathrm{Y}$ en el confín la tribu y los despojos.

Te imagino severo, un poco triste.

Quién me dirá cómo eras y quién fuiste.

Junin, 1966

(p. 267).

Variaciones sobre temas eternos y muy suyos. Dobles que se reflejan y difieren, con simultáneo ejercicio de fusión y separación inevitables. Marcados por las semejanzas (nombre y sangre), las oposiciones (hombre común/hombre heroico; sueño de bronce del guerrero/voz trunca del poeta), las imposibilidades (lugar donde se vivió y nunca se vivió: "Vuelvo a Junín, donde no estuve nunca"; visión que uno desea recuperar a través de la ce-

${ }^{14} \mathrm{El}$ espléndido relato explota inversiones y unificaciones de contrarios: la oposición de barbarie (indígena, lombarda) y civilización (inglesa, romana); bárbaro que elige la civilización y civilizado que elige la barbarie; secretas atracciones por lo esplendoroso o lo aberrante; destinos y fidelidades inexplicables que arrastran a los hombres. "La otra le contestó que era feliz y volvió, esa noche, al desierto. Francisco Borges moría poco después, en la revolución del 74; quizá mi abuela, entonces, pudo percibir en la otra mujer, también arrebatada y trasformada por este continente implacable, un espejo monstruoso de su destino..." (p. 53) "...Acaso las historias que he referido son una sola historia" (p. 54) concluye Borges, e indirectamente es así porque antes ha dicho que el bárbaro de Droctulft pudo engendrar a Dante (p. 51), lo cual implica una encubierta señal a que la inglesa y este continente bárbaro pueden desembocar en el poeta Borges. 
guera de otro - tema de la ceguera propia y la del padre que no alcanzó al abuelo batallador, pero sí a todos los hombres).

Unión de contrastes entre el tono de la epopeya ("que detuvo las lanzas del desierto", "tu sueño de bronce", "El épico Junín de tus soldados") y el de la vida cotidiana y pacífica ("El árbol que plantaste, los cercados") que siempre es la de la sorda amenaza ("Y en el confín la tribu y los despojos").

En esta fusión fantasmal de nieto y abuelo, "El otro, el mismo", se repite la entonación melancólica junto a la épica como en los demás poemas comentados. Pero aquí, además del Yo narrador se introduce el Borges personaje, lo que le permite que por una parte describa y por otra trasmita la emoción de fundir su visión con la hipotética visión del abuelo vivo, su propia emoción con la hipotética emoción y el deseo del abuelo muerto ("acaso").

También alterna la forma descriptiva o narrativa, con la apelación y la interrogación dubitativa a un Tú que es ese mismo fantasma, a veces con reforzada impostación retórica.

El dístico final ${ }^{15}$ encierra la capacidad de producir la emoción sin el conocimiento, sólo por el poder de crear una imagen con la explícita afirmación de su ausencia, por ese juego de entregar y negar lo entregado, de describir y de que lo descrito sea ur vacío, con un interrogante que declara una imposibilidad: "T€ imagino severo, un poco triste. / Quién me dirá cómo eras ) quién fuiste"'16.

5. Servirá para completar esta serie un poema que dedicó al ar ma que perteneció al abuelo Borges: "La suerte de la espada" Lo publicó en libro en la serie de volúmenes individuales, en $L$ moneda de hierro, Emecé, Buenos Aires, 1976 y luego lo incluyó eI su Obra poética, 1923-1977, hasta la última, la $17^{\mathrm{a}}$ ed., 1987, po

15 Tanto este poema como el anterior adoptan la forma de los sonetos d Shakespeare, catorce versos agrupados en tres cuartetos y un dístico fina aunque con otra preferencia en la rima de lo cuartetos (abba).

${ }^{16}$ Las semblanzas del coronel Borges están de acuerdo en mostrarlo ir servado - distinto de su comportamiento a otros militares abiertos y dichar: cheros con sus camaradas-, de conducta equilibrada e intachable. La aces tuación de la nota severa y melancólica surge tal vez de la coincidencia de imagen fijada por los retratos, y de la tradición oral y escrita (pienso en esp cial en los Croquis y siluetas militares de Eduardo Gutiérrez que sin duda c nocía el nieto) y las memorias familiares, unidos a un Yo poético en el q1 predominan la expresión de la soledad y la incomunicación radical del hor bre, aceptada con estoicismo. 
la cual cito. En las "Notas" correspondientes al grupo de La moneda de hierro dice: "Esta composición es el deliberado reverso de Juan Muraña y del Encuentro [sic] que datan de 1970" p. 508. Se refiere a dos cuentos de El informe de Brodie, Emecé, Buenos Aires, 1970, pp. 63-72 y 49-61.

\section{LA SUERTE DE LA ESPADA}

La espada de aquel Borges no recuerda

Sus batallas. La azul Montevideo

Largamente sitiada por Oribe,

El Ejército Grande, la anhelada

Y tan fácil victoria de Caseros,

El intrincado Paraguay, el tiempo,

Las dos balas que entraron en el hombre,

$\mathrm{El}$ agua maculada por la sangre,

Los montoneros en el Entre Ríos,

La jefatura de las tres fronteras,

El caballo y las lanzas del desierto,

San Carlos y Junín, la carga última...

Dios le dio resplandor y estaba ciega.

Dios le dio la epopeya. Estaba muerta.

Quieta como una planta nada supo

De la mano viril ni del estrépito

$\mathrm{Ni}$ de la trabajada empuñadura

$\mathrm{Ni}$ del metal marcado por la patria.

Es una cosa más entre las cosas

Que olvida la vitrina de un museo,

Un símbolo y un humo y una forma

Curva y cruel y que ya nadie mira.

Acaso no soy menos ignorante (p. 485).

El hecho de que sea "el deliberado reverso" supone que los tres deben tener un esquema común para poder ser conscientemente invertidos. En efecto suponen la existencia de un objeto forjado para matar y utilizado para matar por un hombre valiente que ha muerto. En los casos de los dos cuentos son objetos "activos", con cierta voluntad misteriosa y propia como para buscar la pelea, es decir incitar a otras manos a que busquen la revancha (el duelo en los dos cuchillos en "El encuentro", la muerte del "gringo" explotador en "Juan Muraña"). En el poema el objeto permanece inerte, sin capacidad de memoria.

Lo curioso es que la inversión adquiere, como en la mayor 
parte de la obra de Borges, una dualidad y una unidad que persisten en manifiesta tensión.

Por una parte, nada parece unir el objeto al hombe que fue su dueño: "no recuerda", "estaba ciega", "estaba muerta", "Quieta como una planta nada supo", "Es una cosa más entre las cosas / que olvida la vitrina de un museo", "Un símbolo y un humo y una forma / [...] que ya nadie mira". Casi se diría que hay un encarnizamiento en la acumulación de sintagmas que rebajan su capacidad para ser instrumento épico, o simplemente de acción (más si se la compara con los modelos de la inversión: cuchillos de peleas de compadritos).

Además estas ñegatividades quedan intensificadas, a veces. por ir yuxtapuestas con contradicciones internas: resplandor / cie. ga, epopeya / muerta. Ello se repite tanto en su relación con el hérot que la empuñó en las gestas como en su propia sustancia concre. ta, por intrincados entramados: "[...] nada supo / De la manc viril ni del estrépito / Ni de la trabajada empuñadura / Ni del me tal marcado por la patria'. El cuerpo del hombre (mano), e cuerpo del objeto (empuñadura, metal), el cuerpo sonoro (estré pito). Las huellas físicas y las abstracciones, las marcas espiri tuales, sentimentales e ideológicas ("mano viril", "trabajad: empuñadura", "'metal marcado por la patria", "una forma curva y cruel"').

El primer verso personifica, con parte del segundo, el objet ("La espada [...] no recuerda") y distancia la relación con s' dueño "aquel Borges" individualizado por el nombre pero a 1 vez alejado por el demostrativo de mayor distancia en nuestr sistema, el que Karl Bühler llamó deixis de fantasía por su mod de señalamiento ${ }^{17}$.

El verso final retoma y tematiza una constante que hemos vi: to aparecer en los poemas de la serie y que caracteriza su form mental: nadie sabe cómo es ni quién es uno mismo o cualquier de los hombres. Quizá esta frase: “Acaso no soy menos ignorar te" resulte algo desmañada en su función de cierre del poem: en otros lugares y en otras versiones puede ser más eficaz.

Inmediatamente después de la apertura el narrador recuerc lo que la espada ha olvidado, como con cierto despego: el Mont

17 "... cuando un narrador lleva al oyente al reino de lo ausente recc dable o al reino de la fantasía constructiva" y realiza en él la mostración. C $\mathrm{K}$. BüHLER, Teoría del lenguaje, trad. Julián Marías, Rev. de Occidente, M drid, 1950, pp. 144 ss. 
video de la época antirrosista, la campaña de Urquiza, la de Entre Ríos contra López Jordán, la guerra extranjera en el Paraguay, las luchas contra los indios en la frontera, y apenas alude al último combate político en "La Verde" que le costó la muerte, bajo la elusiva frase: "la carga última..." De todo este curriculum guerrero que retoma los de los poemas 1 y 2 de la serie que he comentado, el momento de mayor realce y desarrollo lo constituye aquí:

El intrincado Paraguay, el tiempo,

Las dos balas que entraron en el hombre, $\mathrm{El}$ agua maculada por la sangre,

Parece notarse en este pasaje un deseo de enfocarlo con el distanciamiento que correspondería a la espada (sujeto textual) con respecto a su dueño, "el hombre", con la adopción del punto de vista de un objeto, que privilegia la acción y el protagonismo de otros objetos (las balas) y resuelve las heridas sufridas por un ser humano, en la relación de dos cosas (agua y sangre) que también actúan una en otra, pero con visión sólo dramatizada por el color. De la serie enumerativa se desgaja "el tiempo", que queda aislado en una percepción inusual por su desconexión con toda percepción humana, que sería la única capaz de justificar su aparición.

La voz poética realza - con la complicidad de Dios-su poder de aniquilar al objeto por el juego de oposiciones entre los dones concedidos y las cualidades negativas de las cosas inertes que los reciben. Pero la reunificación final de cosa, persona y Yo los iguala en el común desconocimiento de sí mismos y del otro.

Curiosa moraleja que hace una señal a la tradición hispánica (y universal) de la naturaleza fugitiva del hombre y la permanencia de lo aparentemente más efímero: monumentos que anhelaban ser eternos construidos por la mano del hombre convertidos en ruinas, ríos que pasan pero subsisten en su labrado cauce. Aquí, sin embargo, la moraleja no hace distinciones y los aniquila a todos: cosas inútiles y olvidadas en vitrinas de museos, hombres también muertos como ellas a pesar de su épica porfía.

Nos hemos quedado hipotético lector mon semblable, mon frère con un puñado de poemas que Borges dedicó explícitamente a su abuelo Francisco. Los escribió en diversas épocas, acaso los corrigió o modificó, pero no se encuentran testimonios concretos de intentos de reelaboración salvo el cambio mínimo de dos fechas. 
Sin embargo pienso que he realizado un trabajo que propone ciertas analogías con el de la genética textual como elaboración de un solo poema en diferentes recorridos (el que publicó y borró. el que agregó y volvió a borrar en otra etapa, el que introduje más adelante y persistió en mantener, y el último que convocó)

Otros poemas y prosas dialogan de algún modo con ellos. E: imposible agotarlos pero aún recordaré unos ejemplos en dos cla ves que en la realidad pertenecieron a polos sociales muy aleja dos. Por una parte los dedicados a su bisabuelo por línea mater na, coronel Suárez (pp. 31 y 186-187, de Obra poética, $17^{\mathrm{a}}$ ed. 1987), el que le legó la carga de Junín en su sangre ${ }^{18}$ y el abuel "Isidoro Acevedo" (pp. 95-96) que convocó para morir una ba talla imaginaria. La línea paterna de "Los Borges" de estirp portuguesa (p. 140) donde confluyen los antepasados de los qu nada sabe o que nada memorable realizaron junto con la enter nación famosa por sus hazañas de navegantes o por la trágic muerte del rey don Sebastián perdido en las arenas del norte d África con la flor de la nobleza, y unido en el recuerdo del poet con la otra cara del falsario que volvió para intentar suplantarl Esta mezcla de hazañas triunfales y fracasos, oscuros contraste se repite en poesías, a veces calculadamente situadas a continu; ción una de otra en el libro. Por ejemplo a "Los Borges"' (p. 141 le sucede "A Luis de Camoens" (p. 141) donde las glorias olv dadas se salvan en la epopeya Os Lusiadas. Sin embargo, aunqr aparentemente se subraye el momento positivo, predomina ur entonación de signo melancólico por ser guerrero y poeta ur misma persona, persona que unida a su pueblo siente en car propia la decadencia suya y la de su nación a la cual retorna

Junto a los jefes militares y los caudillos que la historia $\mathbf{r}$ cuerda, estaban presentes en los textos que he estudiado los $\mathrm{p}_{i}$ sanos que los acompañaron en las luchas de la independencia

18 "Mateo, XXV, 30", p. 188. Deseo llamar la atención sobre el her de que la palabra Junín convoca por su sola presencia no sólo las dos genez gías de Jorge Luis Borges sino los dos lugares geográfica e históricamente versos (la batalla en que Bolívar sella la liberación de América en 1824 - ji to con la hazaña de Sucre en Ayacucho- y las sórdidas luchas de front que tuvieron a Junín como comandancia en la provincia de Buenos Air Para una visión crítica de las relaciones con los indios cf. Álvaro Barr Fronteras y territorios federales de las pampas de sur (1872), $2^{\text {a }}$ ed., Hachette, B nos Aires, 1957; David VIÑas, Indios, ejército y fronteras, Siglo XXI, Méx 1982; Tulio Halperín Donghi, José Hernández y sus mundos, Sudamerica Buenos Aires, 1985. 
en las luchas civiles, incluidos (aludidos) en el mismo círculo abstracto de la llanura; a ellos dedica "Los gauchos" (pp. 338339), "El gaucho" (pp. 379-380). Como el abuelo Francisco Borges, como_el autor del poema, como cualquiera de los seres humanos (abarcados por el inclusivo "nosotros") mueren sin saber quiénes o qué eran: "Nunca dijo: Soy gaucho. Fue su suerte / No imaginar la suerte de los otros. / No menos ignorante que nosotros, / No menos solitario, entró en la muerte"' (p. 380).

Como lo comprueba la obra de Borges, ese inclusivo nosotros al que antes aludí puede incorporar al gaucho por monstruoso que sea su destino de degollador, pero no a los indios. Un caso límite lo constituye "Andrés Armoa" 19 pp. 592-593, quizá guaraní o mestizo de guaraní, que estuvo en San Carlos con el abuelo. Algunos de los soldados criollos lo sienten distinto ("como si fuera un hereje o infiel"). Aunque tiene la tarea y ha olvidado las cabezas seccionadas, recuerda la primera que le tocó (de un pampa). El autor lo describe con los rasgos y actitudes no mitificadores que puso en los gauchos, pero que ambiguamente luchan contra la idealización a lo Güiraldes con otro mito de inocente crueldad y de lealtades irracionales y soledad. La frase final que cierra el texto, acentúa esa nota ambigua y escandalosa: "Es amigo de un indio". Otro texto en prosa es el complemento, en economía verbal y monstruosidad: "El otro duelo", El informe de Brodie, Emecé, Buenos Aires, pp. 101-108. Lo sitúa en el Uruguay - lugar en que la experiencia argentina figura siempre en él como más auténtica, más primitiva y más cercana a las fuentes- después de una batalla entre blancos y colorados. La celebración de la victoria colorada por el jefe Nolan, "una de sus diabluras', consiste en una carrera de gente degollada en el momento de partir que se esfuerza por ver quién gana. Jefes, oficiales y soldados de uno y otro bando gozan y apuestan (aún los del bando vencido que serán luego degollados también). El contraste del tono festivo en la narración (y al mismo tiempo indiferente al dolor) con el horror de lo narrado los iguala a todos en un nosotros incluyente sin jerarquías, pero puede leerse con un peso reprobatorio contra el jefe (y los civilizados). Sin embargo, su efecto de anécdota contada a un Yo en un impreciso pasado, venida de boca de otros y rememorada en un impreciso presente desvía la connotación negativa al inquirir sobre algo que no es

${ }^{19}$ En nota, p. 624 indica: "El lector debe imaginar que su historia ocurre en Buenos Aires, hacia mil ocohocientos setenta y tantos'. 
ese horror sino nuestro común destino de hombres. "¿Cómo recuperar, al cabo de un siglo, la oscura historia de dos hombres, sin otra fama que la que les dio su duelo final?" pp. 101-102 se pregunta y contesta al terminar "Había ganado y tal vez no lo supo nunca"' (p. 108).

Sin aspirar a agotar los $\operatorname{casos}^{20}$, recordaré brevemente otras réplicas del poema "Junín" que son reflejos especulares situados en la línea materna. "Acevedo" p. 340, está dedicado a los campos y al lugar que no ha visto; en cambio "La busca" pp. 371372 cuenta otra peregrinación a las fuentes, cuando después de que se han sucedido tres generaciones va por un solo día y una sola noche a conocerlos (re-conocerlos), a revivir " [...] las lanzas del desierto $[\ldots]$ " duplicadas en " $[\ldots]$ los hierros de la reja [...]" que las detuvo (los mismos hierros-lanzas del recinto de la biblioteca paterna), las luchas a caballo, las proscripciones, la llanura, los estancieros dueños de la tierra, los descendientes sedentarios que ya no son los dueños de la tierra, y quizá la unión en el sueño y en la muerte con los desconocidos antepasados.

No he seguido entre textos y pretextos el sinuoso camino d $\epsilon$ la escritura; he intentado en cambio leer un abanico de poemas que se correlacionan de un modo directo o indirecto y subterrá. neo, siguiendo senderos que se bifurcan o convergen en la crea. ción poética y sus vías de acceso a mundos posibles.

Ana María Barreneche $f$ Universidad de Buenos Aire

${ }^{20}$ Pueden surgir en las ocasiones más inesperadas. Por ejemplo en " Ni hon", suma de "delicados laberintos" que "no me fue dado penetrar" p. 622. En ella pasa de laberintos metafísicos occidentales a los laberintc orientales del Japón. Inesperadamente concluye con el asombro de los indic pampas ante objetos cotidianos de los blancos: "A la guarnición de Junín lle gaban hacia 1870 indios pampas, que no habían visto nunca una puerta, $\mathrm{u}$ llamador de bronce o una ventana. Veían y tocaban esas cosas, no menos ré ras para ellos que para nosotros Manhattan, y volvían al desierto". De la en meración caótica declara a propósito de otro poema que ha abusado de ella y qu "debe parecer un caos, un desorden y ser íntimamente un cosmos, un o: den", p. 624. 